\title{
Association between Body Mass Index and Serum Dehydroepiandrosterone Sulfate Level in 8-Year-Old Girls
}

\author{
Ji-Hyun Na, Young-Hwan Kim, Suk-Jin Hong, Jin-Kyung Kim* \\ Department of Pediatrics, Daegu Catholic University School of Medicine, Daegu, Korea
}

Background: Adiposity may play a role as a potential trigger for adrenarche. The purpose of this study was to evaluate the association between body mass index (BMI) and serum dehydroepiandrosterone sulfate (DHEAS) level.

Methods: The medical records of 8-year-old girls who presented to our clinic between 2014 and 2016 with concerns regarding pubertal changes were retrospectively reviewed. The 192 girls were divided into two groups depending on activation of the hypothalamic-pituitary-gonadal (HPG) axis. Group I included 77 subjects with a breast Tanner stage 1 with unknown HPG axis or thelarche without activated HPG axis. Group II included 115 subjects with activated HPG axis. Serum DHEAS level $\geq 1.1 \mu \mathrm{mol} / \mathrm{L}$ was regarded as biochemical adrenarche. Results: Based on correlation analyses, BMI standard deviation score (SDS) was positively correlated with height SDS, bone age divided by chronological age (BA/CA), and DHEAS level in all subjects $(r=0.269, r=0.270$, $\mathrm{r}=0.298$; all $P<0.001$, respectively). BMI SDS was negatively correlated with peak luteinizing hormone level in group II ( $r=-0.236, P=0.011)$. Based on multiple linear regression analyses, BMI SDS was associated with serum DHEAS level in all subjects $(\beta=0.280, P<0.001)$, group I $(\beta=0.415, P=0.001)$, and group II $(\beta=0.206, P=0.030)$. DHEAS level was also associated with $B A / C A$ in all subjects $(\beta=0.402, P<0.001)$, group I $(\beta=0.494, P<0.001)$, and group II $(\beta=0.347, P<0.001)$.

Conclusion: BMI SDS was associated with DHEAS level, which was associated with BA/CA. Childhood obesity may influence the development of adrenarche, which may contribute to advanced skeletal maturation.

Received January 23, 2018

Reviewed February 20, 2018

Accepted April 23, 2018

${ }^{*}$ Corresponding author

Jin-Kyung Kim

https://orcid.org/0000-0003-0018-851X

Department of Pediatrics, Daegu

Catholic University School of Medicine, 33 Duryugongwon-ro 17-gil, Nam-gu,

Daegu 42472, Korea

Tel: $+82-53-650-4597$

Fax: +82-53-650-4243

E-mail:kimjk@cu.ac.kr

Key words: Biochemical adrenarche, Dehydroepiandrosterone sulfate, Body mass index

\section{INTRODUCTION}

Pubertal maturation consists of two processes, gonadarche and adrenarche. Gonadarche is the secretion of gonadal sex steroids by pubertal activation of the hypothalamic-pituitary-gonadal (HPG) axis. The age of onset in girls is typically between 8 and 13 years. ${ }^{1}$ Adrenarche refers to a maturational increase in adrenal androgen production. ${ }^{2,3}$ Adrenarche is characterized by expansion of the adrenal zona reticularis, unique expression of steroidogenic enzymes and cofactors ${ }^{46}$, and changes in the pattern of adrenal biosynthetic and secretory response to adrenocorticotropic hormone (ACTH). In adrenarche, 17-ketosteroid responsiveness to ACTH increases, while cortisol responsiveness to ACTH remains unchanged.' Therefore, adrenarche leads to increased production of adrenal androgens, dehydroepiandrosterone (DHEA), and its sulfate ester (dehydroepiandrosterone sulfate [DHEAS]), but no increase in cortisol level. ${ }^{2-4}$ While the clinical signs of adrenal androgen action are normally observed after the age of 8 years, the increase in adrenal androgen production associated with adrenarche generally begins at approximately 6-8 years of age. ${ }^{3}$ DHEAS has a much lower

Copyright (C) 2018 Korean Society for the Study of Obesity

(a) This is an Open Access article distributed under the terms of the Creative Commons Attribution Non-Commercial License (http://creativecommons.org/licenses/by-nc/4.o/) which permits unrestricted non-commercial use, distribution, and reproduction in any medium, provided the original work is properly cited. 
rate of clearance from the circulation than DHEA. DHEAS has neither a diurnal rhythm nor day-to-day variation. Serum DHEAS level is the best marker of adrenal androgen secretion. ${ }^{2,3}$ DHEAS levels above $1.1 \mu \mathrm{mol} / \mathrm{L}$ are regarded as a biochemical hallmark of adrenarche. ${ }^{2,3}$ Guran et al. ${ }^{8}$ reported the cut-off age for an increase in DHEAS above $1.1 \mu \mathrm{mol} / \mathrm{L}$ is 8 years for girls and 7 years for boys. High prepubertal DHEAS level is associated with premature adrenarche (PA), defined as the appearance of clinical signs of adrenarche before the age of 8 years in girls, along with elevated DHEAS level for that age. Although PA is usually considered benign, in some girls, PA has been associated with several metabolic disturbances including hyperinsulinemia, dyslipidemia, or polycystic ovary syndrome. ${ }^{2,3}$ The initiation mechanisms of adrenarche remain mostly unclear although adiposity may play a role as a potential trigger., ${ }^{2,3}$ Previous studies have shown that low birth weight and small size for gestational age are associated with higher prepubertal adrenal androgen production, mainly in girls, especially if accompanied by rapid weight gain in early childhood. ${ }^{9-13}$ Higher prepubertal adrenal androgen production has also been reported in obese children with normal birth weight. ${ }^{13-15}$ Therefore, we retrospectively evaluated the medical records of 8-year-old girls to investigate the associations between body mass index (BMI) and serum DHEAS level.

\section{METHODS}

\section{Subjects}

We retrospectively reviewed the medical records of 8-year-old girls who visited Daegu Catholic University Medical Center between January 2014 and December 2016 with concerns regarding pubertal changes. In the present study, 192 healthy girls who underwent medical and physical examinations were evaluated. All subjects were born at term with a birth weight $\geq 2,500 \mathrm{~g}$. Girls with chronic diseases, organic brain lesions, or receiving any drug treatment or exogenous hormone therapy were excluded. Pubertal status (breast development and pubic hair) was also recorded. Gonadotropin-releasing hormone ( $\mathrm{GnRH}$ ) stimulation test was conducted in 178 girls. The subjects were divided into two groups depending on activation of the HPG axis. Group I included 77 subjects with a breast Tanner stage 1 with unknown HPG axis or the- larche without activation of the HPG axis, and group II included 115 subjects with activated HPG axis. This study was approved by the Institutional Review Board of the Daegu Catholic University Medical Center, Daegu, Korea (IRB No. CR-17-060). The need for informed consent was waived by the board.

\section{Measurement and laboratory evaluation}

The height and weight of each patient were measured, and BMI was calculated by dividing weight $(\mathrm{kg})$ by squared height $\left(\mathrm{m}^{2}\right)$. Height, weight, and BMI were expressed as a standard deviation score (SDS) according to age- and sex-matched growth charts of Korean children and adolescents published in 2007 by the Korea Centers for Disease Control and Prevention and the Korea National Institute of Health. ${ }^{16}$ Normal weight was defined as a BMI $<85$ th percentile for age and sex, and overweight/obese was defined as a BMI $\geq 85$ th percentile for age and sex. Sexual maturity ratings were determined according to the Marshall and Tanner staging method. ${ }^{17}$ Bone age (BA) was assessed using radiographs of the left hand according to the method of Greulich and Pyle. ${ }^{18}$ Bone age divided by chronological age (BA/CA) was used as an index of BA advancement. In subjects with thelarche, the GnRH stimulation test was performed by intravenous administration of $100 \mu \mathrm{g}$ of gonadorelin (Relefact; Sanofi-Aventis, Frankfurt am Main, Germany) for the diagnosis of gonadarche. Activation of the HPG axis was defined by peak luteinizing hormone (LH) level $\geq 5 \mathrm{IU} / \mathrm{L}$ using the GnRH stimulation test. ${ }^{19}$ Serum LH level was measured using an electrochemiluminescence immunoassay on a Cobas 8000 modular analyzer (Roche Diagnostics, Mannheim, Germany). Serum DHEAS concentration was measured using chemiluminescence immunoassay on an Immulite 2000 XPi System (Siemens Healthcare Diagnostics, Flanders, NJ, USA). Biochemical adrenarche was defined as an increase in circulating adrenal androgen concentration with a serum DHEAS level $\geq 1.1 \mu \mathrm{mol} / \mathrm{L}^{2,3}$

\section{Statistical analysis}

All statistical analyses were performed using IBM SPSS version 20.0 (IBM Corp., Armonk, NY, USA). Values are presented as mean \pm standard deviation for continuous variables. Student $t$-test and Mann-Whitney $U$-test were applied for comparison between two groups. The chi-square test was used to compare proportions. 
Correlations were evaluated using Spearman correlation coefficient. Multivariate linear regression analyses were performed to investigate the influence of clinical and biochemical variables on the changes in serum DHEAS level and the degree of advanced skeletal maturation (BA/CA). A $P$-value $<0.05$ was considered statistically significant.

\section{RESULTS}

\section{Anthropometric characteristics and hormonal status of the study population}

Medical records of 192 girls aged 8 years were evaluated. Group I included 77 girls and group II included 115 girls. The mean BA/CA was $1.09 \pm 0.11$ in group I and $1.13 \pm 0.09$ in group II $(P=0.009)$. The mean BMI SDS was $0.8 \pm 1.1$ in group I and $0.3 \pm 1.2$ in group II $(P=0.003)$. The mean DHEAS level was $1.3 \pm 0.9 \mu \mathrm{mol} / \mathrm{L}$ in group I and 1.2 $\pm 0.8 \mu \mathrm{mol} / \mathrm{L}$ in group II. Biochemical adrenarche was observed in 34 girls (44.2\%) in group I and 49 girls (42.6\%) in

Table 1. Anthropometric characteristics and hormonal status of the subjects

\begin{tabular}{|c|c|c|c|}
\hline Variable & $\begin{array}{l}\text { Group I } \\
(\mathrm{n}=77)\end{array}$ & $\begin{array}{l}\text { Group II } \\
(n=115)\end{array}$ & $P$ \\
\hline CA (yr) & $8.6 \pm 0.3$ & $8.6 \pm 0.3$ & 0.106 \\
\hline$B A(y r)$ & $9.3 \pm 0.9$ & $9.7 \pm 0.8$ & 0.001 \\
\hline $\mathrm{BA} / \mathrm{CA}$ & $1.09 \pm 0.11$ & $1.13 \pm 0.09$ & 0.009 \\
\hline Height (cm) & $132.6 \pm 4.7$ & $132.7 \pm 5.3$ & 0.907 \\
\hline Height SDS & $0.8 \pm 0.9$ & $0.8 \pm 1.0$ & 0.919 \\
\hline $\mathrm{BMI}\left(\mathrm{kg} / \mathrm{m}^{2}\right)$ & $18.8 \pm 2.7$ & $17.7 \pm 2.8$ & 0.006 \\
\hline BMI SDS & $0.8 \pm 1.1$ & $0.3 \pm 1.2$ & 0.003 \\
\hline LH peak & $3.2 \pm 1.1^{*}$ & $12.6 \pm 10.3$ & $<0.001^{\dagger}$ \\
\hline DHEAS $(\mu \mathrm{mol} / \mathrm{L})^{\ddagger}$ & $1.3 \pm 0.9$ & $1.2 \pm 0.8$ & $0.694^{+}$ \\
\hline Biochemical adrenarche & $34(44.2)$ & $49(42.6)$ & $0.832^{\S}$ \\
\hline Overweight/obese & $33(42.9)$ & $26(22.6)$ & $0.004^{\S}$ \\
\hline Tanner stage, breast, I/II/III/IVN & $14 / 59 / 4 / 0 / 0$ & 0/81/31/3/0 & - \\
\hline Tanner stage, pubic hair, I/II/III/IVN & 0/4/0/0/0 & 0/2/0/0/0 & - \\
\hline
\end{tabular}

Values are presented as mean \pm standard deviation or number (\%). Student $t$-test was applied for comparison between the two groups. Group I included subjects with a breast Tanner stage 1 with unknown HPG axis or thelarche without activation of the HPG axis, and group II included subjects with activated HPG axis.

${ }^{*}$ Gonadotropin-releasing hormone stimulation test was conducted in 63 of 77 girls in group I and all girls in group II; 'Mann-Whitney U-test was applied for comparison be-

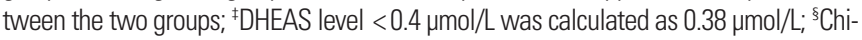
square test was applied to compare proportions.

$\mathrm{CA}$, chronological age; $\mathrm{BA}$, bone age; $\mathrm{BA} / \mathrm{CA}$, bone age divided by chronological age; SDS, standard deviation score; BMI, body mass index; LH peak, peak stimulated luteinizing hormone level; DHEAS, dehydroepiandrosterone sulfate; HPG, hypothalamic-pituitary-gonadal. group II. The number of overweight/obese girls was higher in group I $(42.9 \%)$ than in group II $(22.6 \%, P=0.004)$ (Table 1$)$.

\section{Correlations and multiple linear regression analysis}

Based on Spearman correlation analyses, BMI SDS was significantly and positively correlated with height SDS, BA/CA, and DHEAS level in all subjects $(r=0.269, r=0.270, r=0.298$; all $P<0.001$, respectively); group I subjects $(\mathrm{r}=0.292, P=0.010$; $\mathrm{r}=0.276, P=0.015 ; \mathrm{r}=0.398, P<0.001$, respectively), and group II subjects $(\mathrm{r}=0.251, P=0.007 ; \mathrm{r}=0.366, P<0.001 ; \mathrm{r}=0.252, P=$ 0.007 , respectively). BMI SDS was significantly and negatively correlated with peak LH level in all subjects $(\mathrm{r}=-0.353, P<0.001)$ and in group II subjects $(\mathrm{r}=-0.236, P=0.011)$ (Table 2).

Based on multiple linear regression analyses, BMI SDS was associated with serum DHEAS level in all subjects $(\beta=0.280, P<$ 0.001 ), group I ( $\beta=0.415, P=0.001)$, and group II $(\beta=0.206, P=$ 0.030 ) (Table 3). DHEAS level was associated with BA/CA in all subjects $(\beta=0.402, P<0.001)$, group I $(\beta=0.494, P<0.001)$, and group II $(\beta=0.347, P<0.001)$ (Table 4$)$.

Table 2. Spearman correlation coefficients of the subjects

\begin{tabular}{|c|c|c|c|c|c|c|c|c|}
\hline \multirow{2}{*}{ Variable } & \multicolumn{2}{|c|}{ BMI SDS } & \multicolumn{2}{|c|}{$\mathrm{BA} / \mathrm{CA}$} & \multicolumn{2}{|c|}{ DHEAS } & \multicolumn{2}{|c|}{ LH peak* $^{*}$} \\
\hline & $r$ & $P$ & $r$ & $P$ & $r$ & $P$ & $r$ & $P$ \\
\hline \multicolumn{9}{|l|}{ Total $(n=192)$} \\
\hline Height SDS & 0.269 & $<0.001$ & 0.407 & $<0.001$ & 0.206 & 0.004 & 0.085 & 0.262 \\
\hline BMI SDS & & & 0.270 & $<0.001$ & 0.298 & $<0.001$ & -0.353 & $<0.001$ \\
\hline $\mathrm{BA} / \mathrm{CA}$ & & & & & 0.487 & $<0.001$ & 0.175 & 0.019 \\
\hline DHEAS & & & & & & & -0.050 & 0.512 \\
\hline \multicolumn{9}{|c|}{ Group I $(n=77)$} \\
\hline Height SDS & 0.292 & 0.010 & 0.316 & 0.005 & 0.291 & 0.010 & 0.055 & 0.670 \\
\hline BMI SDS & & & 0.276 & 0.015 & 0.398 & $<0.001$ & 0.007 & 0.959 \\
\hline $\mathrm{BA} / \mathrm{CA}$ & & & & & 0.578 & $<0.001$ & -0.027 & 0.834 \\
\hline DHEAS & & & & & & & 0.069 & 0.594 \\
\hline \multicolumn{9}{|c|}{ Group II (n=115) } \\
\hline Height SDS & 0.251 & 0.007 & 0.482 & $<0.001$ & 0.150 & 0.110 & 0.167 & 0.075 \\
\hline BMI SDS & & & 0.366 & $<0.001$ & 0.252 & 0.007 & -0.236 & 0.011 \\
\hline $\mathrm{BA} / \mathrm{CA}$ & & & & & 0.453 & $<0.001$ & 0.123 & 0.190 \\
\hline DHEAS & & & & & & & -0.090 & 0.339 \\
\hline
\end{tabular}

Group I included subjects with a breast Tanner stage 1 with unknown HPG axis or thelarche without activation of the HPG axis, and group II included subjects with activated HPG axis.

${ }^{*}$ Gonadotropin-releasing hormone stimulation test was conducted in 178 girls. BMI, body mass index; SDS, standard deviation score; BA/CA, bone age divided by chronological age; DHEAS, dehydroepiandrosterone sulfate; LH peak, peak stimulated luteinizing hormone level; HPG, hypothalamic-pituitary-gonadal. 
Table 3. Multiple linear regression analysis of factors affecting serum DHEAS level in 8-year-old girls

\begin{tabular}{|c|c|c|c|c|c|c|c|c|c|c|c|c|}
\hline \multirow{2}{*}{ Variable } & \multicolumn{4}{|c|}{ All subjects $(n=192)$} & \multicolumn{4}{|c|}{ Group I ( $n=77)$} & \multicolumn{4}{|c|}{ Group II (n=115) } \\
\hline & B & SE & $\beta$ & $P$ & B & SE & $\beta$ & $P$ & B & SE & $\beta$ & $P$ \\
\hline CA & -0.682 & 4.892 & -0.010 & 0.889 & -1.795 & 9.144 & -0.023 & 0.845 & -0.618 & 5.667 & -0.010 & 0.913 \\
\hline BMI SDS & 7.461 & 1.988 & 0.280 & $<0.001$ & 14.833 & 4.236 & 0.415 & 0.001 & 4.932 & 2.243 & 0.206 & 0.030 \\
\hline LH peak & -0.145 & 0.240 & -0.045 & 0.545 & -0.992 & 3.889 & -0.030 & 0.800 & -0.242 & 0.250 & -0.090 & 0.335 \\
\hline Adjusted $\mathrm{R}^{2}$ & \multicolumn{4}{|c|}{0.071} & \multicolumn{4}{|c|}{0.133} & \multicolumn{4}{|c|}{0.029} \\
\hline
\end{tabular}

Group I included subjects with a breast Tanner stage 1 with unknown HPG axis or thelarche without activation of the HPG axis, and group II included subjects with activated HPG axis.

DHEAS, dehydroepiandrosterone sulfate; B, unstandardized coefficients; SE, standard error; $\beta$, standardized coefficients; CA, chronological age; BMI, body mass index; SDS, standard deviation score; LH peak, peak stimulated luteinizing hormone; HPG, hypothalamic-pituitary-gonadal.

Table 4. Multiple linear regression analysis of factors affecting BA/CA in 8-year-old girls

\begin{tabular}{|c|c|c|c|c|c|c|c|c|c|c|c|c|}
\hline \multirow{2}{*}{ Variable } & \multicolumn{4}{|c|}{ All subjects ( $n=192)$} & \multicolumn{4}{|c|}{ Group I (n=77) } & \multicolumn{4}{|c|}{ Group II $(n=115)$} \\
\hline & B & SE & $\beta$ & $P$ & B & SE & $\beta$ & $P$ & B & SE & $\beta$ & $P$ \\
\hline Height SDS & 0.036 & 0.007 & 0.335 & $<0.001$ & 0.034 & 0.014 & 0.273 & 0.020 & 0.037 & 0.007 & 0.391 & $<0.001$ \\
\hline BMI SDS & 0.007 & 0.006 & 0.080 & 0.231 & -0.001 & 0.014 & -0.005 & 0.971 & 0.013 & 0.006 & 0.166 & 0.034 \\
\hline DHEAS & 0.001 & 0.000 & 0.402 & $<0.001$ & 0.002 & 0.000 & 0.494 & $<0.001$ & 0.001 & 0.000 & 0.347 & $<0.001$ \\
\hline LH peak & 0.002 & 0.001 & 0.196 & 0.002 & -0.005 & 0.011 & -0.052 & 0.620 & 0.001 & 0.001 & 0.148 & 0.052 \\
\hline Adjusted $R^{2}$ & \multicolumn{4}{|c|}{0.381} & \multicolumn{4}{|c|}{0.334} & \multicolumn{4}{|c|}{0.406} \\
\hline
\end{tabular}

Group I included subjects with a breast Tanner stage 1 with unknown HPG axis or thelarche without activation of the HPG axis, and group II included subjects with activated HPG axis.

BA/CA, bone age divided by chronological age; B, unstandardized coefficients; SE, standard error; $\beta$, standardized coefficients; SDS, standard deviation score; BMI, body mass index DHEAS, dehydroepiandrosterone sulfate; LH peak, peak stimulated luteinizing hormone; HPG, hypothalamic-pituitary-gonadal.

\section{DISCUSSION}

A distinct interindividual variation was observed not only in the timing of adrenarche, but also in the amount of adrenal androgen precursor production. ${ }^{2,3}$ In this study, serum DHEAS level showed a wide distribution from $0.4 \mu \mathrm{mol} / \mathrm{L}$ to $5.1 \mu \mathrm{mol} / \mathrm{L}$. Serum DHEAS level was below $0.4 \mu \mathrm{mol} / \mathrm{L}$ in 20 of 192 girls. The prevalence of biochemical adrenarche in all subjects with concerns regarding pubertal changes was $43.2 \%$ ( $44.2 \%$ of girls without HPG axis activation and $42.6 \%$ of girls with HPG axis activation). In most girls without HPG axis activation, thelarche may reflect the peripheral source of sex steroids. However, in several girls, the degree of thelarche progressed during the follow-up period, which might be associated with activation of the HPG axis. Furthermore, some of the overweight/obese girls may have experienced HPG axis activation. Recent studies have shown that obesity affects the $\mathrm{LH}$ response to the GnRH stimulation test in girls. ${ }^{20,21}$ During the GnRH stimulation test, peak LH level was significantly lower in obese and overweight subjects than in normal weight subjects, in Tanner stage 2 and 3 girls. ${ }^{21}$ BMI was negatively correlated with peak LH level. ${ }^{20}$ In this study, BMI SDS was also negatively correlated with peak LH level. Therefore, it is difficult to conclude that the prevalence of biochemical adrenarche in girls with gonadarche (activation of HPG axis) was lower than in girls without activation of the HPG axis.

The present study included 83 girls with biochemical adrenarche. However, only six of these 83 girls presented with pubarche, four of whom presented with pubarche without thelarche. Pubarche in these four girls was due to the development of adrenarche. The clinical presentation of adrenarche did not always correlate with serum DHEAS concentration. DHEA and DHEAS are very weak androgen receptor agonists that undergo extraglandular metabolism to produce active androgen, which activates the androgen receptor. The appearance of clinical signs varies depending on the peripheral metabolism and sensitivity to androgens. ${ }^{2,3}$ In addition, the conversion to active androgens in peripheral adipose tissue may be enhanced by obesity.22

In several studies, obese children were reported to have BA that 
exceeded their CA, which leads to relatively tall stature before puberty and during early puberty, but not to a tall adult height. ${ }^{23,24}$ Kim et al. ${ }^{25}$ reported that advanced skeletal maturation is associated with elevated DHEAS level in obese children and adolescents. In the present study, serum DHEAS level was significantly associated with BA/CA in all subjects. BMI SDS was significantly correlated with $\mathrm{BA} / \mathrm{CA}$, whereas, in the multivariate analysis, a significant association was demonstrated only in subjects with HPG axis activation. BMI SDS was significantly associated with DHEAS level in all subjects, not only in subjects with HPG axis activation.

In several studies, prepubertal adrenal androgen production has been reported to be higher in obese children. ${ }^{14,15,26-30}$ Children with higher DHEAS level were reported to be fatter and tended to be taller and have a higher BA than their counterparts. ${ }^{14}$ An increase in BMI in children is associated with an increase in urinary excretion of DHEAS, and BMI gains correlate with DHEAS. ${ }^{27}$ Obese prepubertal children $(8.5 \pm 2.1$ years $)$ showed significantly increased DHEAS level compared with normal weight children. After 1 year of lifestyle intervention, while levels of other steroids were found to normalize with weight loss, the elevated DHEAS level did not. This finding indicates an irreversible maturation of the zona reticularis of the adrenal gland even after successful weight loss. ${ }^{30}$

DHEA is synthesized by 17- $\alpha$-hydroxylase/17,20-lyase and metabolized by $3 \beta$-hydroxysteroid dehydrogenase type 2 (3ß-HSD2) and DHEA-sulfotransferase. Enhancing the 17,20-lyase activity or decreasing the activity of $3 \beta-H S D 2$ was shown to play a role in the onset of adrenarche. ${ }^{2,3}$ Insulin, insulin-like growth factor-1 (IGF-1), and leptin have been suggested to mediate the effect of obesity on the initiation of adrenarche. ${ }^{31-34}$ However, IGF-1 is likely associated with adrenal growth in early childhood rather than zona reticularis regulation. ${ }^{35}$ An increase in the intra-adrenal concentration of cortisol during childhood growth may lead to inhibition of $3 \beta-\mathrm{HSD} 2$ activity. ${ }^{36}$ Leptin may enhance the 17,20-lyase activity of adrenal cells. ${ }^{37}$ Reportedly, body fat mass is closely associated with systemic leptin level ${ }^{38}$ and 17,20-lyase activity in prepubertal girls. ${ }^{39}$

The present study has several limitations. First, the single clinicbased retrospective design may lead to selection bias. Second, the sample size of overweight/obese girls was relatively small, so the relationship of BMI might have been underestimated. Third, BMI percentiles were used to classify obesity. Although BMI is a good measure for overweight, it is limited as an indirect measurement of fat mass.

In conclusion, BMI SDS was associated with DHEAS level, which was associated with BA/CA. We postulate that childhood obesity may influence the development of adrenarche, which is associated with advanced skeletal maturation. Future studies including a large sample of Korean children are needed to investigate the influence of obesity on adrenarche.

\section{CONFLICTS OF INTEREST}

The authors declare no conflict of interest.

\section{REFERENCES}

1. Bordini B, Rosenfield RL. Normal pubertal development. Part II: clinical aspects of puberty. Pediatr Rev 2011;32:281-92.

2. Utriainen P, Laakso S, Liimatta J, Jääskeläinen J, Voutilainen R. Premature adrenarche: a common condition with variable presentation. Horm Res Paediatr 2015;83:221-31.

3. Voutilainen R, Jääskeläinen J. Premature adrenarche: etiology, clinical findings, and consequences. J Steroid Biochem Mol Biol 2015;145:226-36.

4. Belgorosky A, Baquedano MS, Guercio G, Rivarola MA. Adrenarche: postnatal adrenal zonation and hormonal and metabolic regulation. Horm Res 2008;70:257-67.

5. Miller WL. Androgen synthesis in adrenarche. Rev Endocr Metab Disord 2009;10:3-17.

6. Rege J, Rainey WE. The steroid metabolome of adrenarche. J Endocrinol 2012;214:133-43.

7. Rich BH, Rosenfield RL, Lucky AW, Helke JC, Otto P. Adrenarche: changing adrenal response to adrenocorticotropin. J Clin Endocrinol Metab 1981;52:1129-36.

8. Guran T, Firat I, Yildiz F, Kaplan Bulut I, Dogru M, Bereket A. Reference values for serum dehydroepiandrosterone-sulphate in healthy children and adolescents with emphasis on the age of adrenarche and pubarche. Clin Endocrinol (Oxf) 2015;82: 712-8.

9. Charkaluk ML, Trivin C, Brauner R. Premature pubarche as an indicator of how body weight influences the onset of adre- 
narche. Eur J Pediatr 2004;163:89-93.

10. Neville KA, Walker JL. Precocious pubarche is associated with SGA, prematurity, weight gain, and obesity. Arch Dis Child 2005;90:258-61.

11. Ibáñez L, Lopez-Bermejo A, Díaz M, Suárez L, de Zegher F. Low-birth weight children develop lower sex hormone binding globulin and higher dehydroepiandrosterone sulfate levels and aggravate their visceral adiposity and hypoadiponectinemia between six and eight years of age. J Clin Endocrinol Metab 2009;94:3696-9.

12. Ong KK, Potau N, Petry CJ, Jones R, Ness AR, Honour JW, et al. Opposing influences of prenatal and postnatal weight gain on adrenarche in normal boys and girls. J Clin Endocrinol Metab 2004;89:2647-51.

13. Nordman H, Voutilainen R, Antikainen L, Jääskeläinen J. Prepubertal children born large for gestational age have lower serum DHEAS concentrations than those with a lower birth weight. Pediatr Res 2017;82:285-9.

14. Corvalán C, Uauy R, Mericq V. Obesity is positively associated with dehydroepiandrosterone sulfate concentrations at $7 \mathrm{y}$ in Chilean children of normal birth weight. Am J Clin Nutr 2013;97:318-25.

15. Mericq V, Pereira A, Uauy R, Corvalán C. Early BMI gain and later height growth predicts higher DHEAS concentrations in 7-year-old chilean children. Horm Res Paediatr 2017;87:15-22.

16. Moon JS, Lee SY, Nam CM, Choi JM, Choe BK, Seo JW, et al. 2007 Korean National Growth Charts: review of developmental process and an outlook. Korean J Pediatr 2008;51:1-25.

17. Marshall WA, Tanner JM. Variations in pattern of pubertal changes in girls. Arch Dis Child 1969;44:291-303.

18. Greulich WW, Pyle SI. Radiographic atlas of skeletal development of the hand and wrist. 2nd ed. Stanford (CA): Stanford University Press; 1959.

19. Carel JC, Eugster EA, Rogol A, Ghizzoni L, Palmert MR; ESPE-LWPES GnRH Analogs Consensus Conference Group, et al. Consensus statement on the use of gonadotropin-releasing hormone analogs in children. Pediatrics 2009;123:e752-62.

20. Fu JF, Liang JF, Zhou XL, Prasad HC, Jin JH, Dong GP, et al. Impact of BMI on gonadorelin-stimulated LH peak in premenarcheal girls with idiopathic central precocious puberty.
Obesity (Silver Spring) 2015;23:637-43.

21. Lee HS, Yoon JS, Hwang JS. Luteinizing hormone secretion during gonadotropin-releasing hormone stimulation tests in obese girls with central precocious puberty. J Clin Res Pediatr Endocrinol 2016;8:392-8.

22. Mäntyselkä A, Jääskeläinen J, Lindi V, Viitasalo A, Tompuri T, Voutilainen $\mathrm{R}$, et al. The presentation of adrenarche is sexually dimorphic and modified by body adiposity. J Clin Endocrinol Metab 2014;99:3889-94.

23. Kleber M, Schwarz A, Reinehr T. Obesity in children and adolescents: relationship to growth, pubarche, menarche, and voice break. J Pediatr Endocrinol Metab 2011;24:125-30.

24. Johnson W, Stovitz SD, Choh AC, Czerwinski SA, Towne B, Demerath EW. Patterns of linear growth and skeletal maturation from birth to 18 years of age in overweight young adults. Int J Obes (Lond) 2012;36:535-41.

25. Kim SE, Jang JW, Ahn MB, Kim SH, Cho WK, Cho KS, et al. The association between skeletal maturation and adrenal androgen levels in obese children and adolescents. Ann Pediatr Endocrinol Metab 2017;22:108-14.

26. l'Allemand D, Schmidt S, Rousson V, Brabant G, Gasser T, Grüters A. Associations between body mass, leptin, IGF-I and circulating adrenal androgens in children with obesity and premature adrenarche. Eur J Endocrinol 2002;146:537-43.

27. Remer T, Manz F. Role of nutritional status in the regulation of adrenarche. J Clin Endocrinol Metab 1999;84:3936-44.

28. Reinehr T, de Sousa G, Roth CL, Andler W. Androgens before and after weight loss in obese children. J Clin Endocrinol Metab 2005;90:5588-95.

29. Shi L, Wudy SA, Buyken AE, Hartmann MF, Remer T. Body fat and animal protein intakes are associated with adrenal androgen secretion in children. Am J Clin Nutr 2009;90:1321-8.

30. Reinehr T, Kulle A, Wolters B, Lass N, Welzel M, Riepe F, et al. Steroid hormone profiles in prepubertal obese children before and after weight loss. J Clin Endocrinol Metab 2013;98: E1022-30.

31. Vuguin P, Linder B, Rosenfeld RG, Saenger P, DiMartinoNardi J. The roles of insulin sensitivity, insulin-like growth factor I (IGF-I), and IGF-binding protein-1 and -3 in the hyperandrogenism of African-American and Caribbean Hispanic 
girls with premature adrenarche. J Clin Endocrinol Metab 1999; $84: 2037-42$.

32. Cizza G, Dorn LD, Lotsikas A, Sereika S, Rotenstein D, Chrousos GP. Circulating plasma leptin and IGF-1 levels in girls with premature adrenarche: potential implications of a preliminary study. Horm Metab Res 2001;33:138-43.

33. Guercio G, Rivarola MA, Chaler E, Maceiras M, Belgorosky A. Relationship between the growth hormone/insulin-like growth factor-I axis, insulin sensitivity, and adrenal androgens in normal prepubertal and pubertal girls. J Clin Endocrinol Metab 2003;88:1389-93.

34. Güven A, Cinaz P, Ayvali E. Are growth factors and leptin involved in the pathogenesis of premature adrenarche in girls? J Pediatr Endocrinol Metab 2005;18:785-91.

35. Baquedano MS, Berensztein E, Saraco N, Dorn GV, de Davila MT, Rivarola MA, et al. Expression of the IGF system in human adrenal tissues from early infancy to late puberty: implications for the development of adrenarche. Pediatr Res 2005;
$58: 451-8$.

36. Topor LS, Asai M, Dunn J, Majzoub JA. Cortisol stimulates secretion of dehydroepiandrosterone in human adrenocortical cells through inhibition of 3betaHSD2. J Clin Endocrinol Metab 2011;96:E31-9.

37. Biason-Lauber A, Zachmann M, Schoenle EJ. Effect of leptin on CYP17 enzymatic ctivities in human adrenal cells: new insight in the onset of adrenarche. Endocrinology 2000;141: 1446-54.

38. Ahmed ML, Ong KK, Morrell DJ, Cox L, Drayer N, Perry L, et al. Longitudinal study of leptin concentrations during puberty: sex differences and relationship to changes in body composition. J Clin Endocrinol Metab 1999;84:899-905.

39. Kim SH, Moon JY, Sasano H, Choi MH, Park MJ. Body fat mass is associated with ratio of steroid metabolites reflecting 17,20-lyase activity in prepubertal girls. J Clin Endocrinol Metab 2016;101:4653-60. 